\title{
Management of ureteric stone in pregnancy: a review
}

\author{
Avinash P. S. Thakur ${ }^{{ }^{*}}$ (D), Vivek Sharma², Vasantharaja Ramasamy ${ }^{3}$, Arpan Choudhary $^{1}$, Prashant Patel ${ }^{1}$, \\ Sangeeta Singh ${ }^{4}$ and Subeesh Parol ${ }^{3}$
}

\begin{abstract}
Background: Urolithiasis in pregnancy is a major health concern and is one of the most common causes for nonobstetrical abdominal pain and subsequent hospital admission during pregnancy. The incidence of urinary calculi during pregnancy varies in the range of $1 / 200$ to 1/2000. Acute ureteric colic in pregnancy is associated with significant potential risks to both mother and fetus. Significant anatomic and functional changes occur in pregnancy which not only lead to stone formation but also create diagnostic dilemma. The diagnosis of ureteric calculi can be incorrect in about $28 \%$ of pregnant patients.
\end{abstract}

Main body: Management of ureteric stone during pregnancy is remaining to be a challenge for the treating urologist. Because of the inability to use good imaging options for the diagnosis confirmation and more invasive approach for the treatment, management continues to be difficult. The main threats are preterm labor with delivery and premature rupture of membranes. Other pregnancy complications are obstructive uropathy, gestational diabetes mellitus, recurrent abortions and pre-eclampsia. Management of diagnosed ureteric stone is unique in the pregnant population and requires multi-disciplinary care. It should be individualized for each patient and moves preferably from conservative to invasive approaches sequentially. With continued advancements in endourological techniques, few definitive treatment options are also available for such patients.

Conclusion: There are several lacunae related with the diagnostic imaging, medical expulsive therapy, reliability of ureteral stent/percutaneous nephrostomy insertions and safety of ureteroscopy during pregnancy. Herein, we review the management of ureteric stone during pregnancy, the various diagnostic modalities and treatment options with their advantages and disadvantages. We also proposed our management algorithm to deal with such clinical scenario in this particular population.

Keywords: Ureteric stones, Pregnancy, Management, URS, Ureteroscopy

\section{Background}

Urolithiasis in pregnancy is a major health concern and is one of the common causes for non-obstetrical abdominal pain and subsequent hospital admission in pregnant women. The incidence of urinary calculi during pregnancy varies in the range of $1 / 200$ to $1 / 2000$, which is not

\footnotetext{
*Correspondence: drapst@gmail.com

1 Department of Urology, Super Speciality Hospital, Netaji Subhash

Chandra Bose Medical College, Jabalpur, M.P., India

Full list of author information is available at the end of the article
}

different from the incidence reported in the nongravid women [1].

Majority of women present in the second or third trimester of their pregnancy, and as compared to primiparous women, multiparous are more frequently affected [2-4]. Stone formation during pregnancy is predisposed by urinary tract dilatation due to ureteric obstruction by gravid uterus, smooth muscle relaxant effect of progesterone and infection [5]. Physiological hydronephrosis can occur in up to $90 \%$ on the right side and $67 \%$ on the left side in pregnancy [6].These normal anatomic changes during pregnancy not only lead to 
stasis and stone formation but also create diagnostic dilemma. In pregnancy, stones are mostly composed of calcium phosphate and more commonly located in ureter rather than renal pelvis $[7,8]$. This is due to the migration of renal stones into the ureter which is favored by physiological dilatation of the collecting system.

Management of ureteric stone during pregnancy is crucial because of the potential risks to the mother and fetus [9]. The main threats are preterm labor with delivery (which can occur in up to $40 \%$ of women) and premature rupture of membranes [10]. Other pregnancy complications are obstructive uropathy, hypertension, higher incidence of caesarean section, gestational diabetes mellitus, recurrent abortions and pre-eclampsia [11-13]. These all potential complications make accurate diagnosis of ureteric stone imperative.

Clinical presentation for ureteric calculi during pregnancy is characterized by colicky or dull aching pain that radiates to lower abdomen or labial region, tenderness, hematuria and fever. On the basis of these symptoms, a preliminary diagnosis can be made, but that can be incorrect in about $28 \%$ of pregnant patients and it can be misdiagnosed as diverticulitis, appendicitis and placental abruption [14].

Because there is limitation in the use of X-rays, intravenous urography and computed tomography in pregnancy due to the teratogenicity, the diagnosis can be difficult $[15,16]$. Ultrasonography (USG) is mostly used as the preferred diagnostic test in pregnant women with suspected ureteric colic due to its lack of ionizing radiation, low cost and availability. Although the specificity of USG is high, it has low sensitivity which can bring in dilemma in the management of ureteric stone during pregnancy.

Regarding management of ureteric stone in pregnancy, it is mainly treated by conservative mode initially with medical expulsive therapy (MET) which is successful in about $70-80 \%$ of patients [17]. In patients with failed initial conservative treatment, double J (DJ) stent insertion or percutaneous nephrostomy (PCN) tube placement can be considered.

Occasionally for symptomatic ureteric stones during pregnancy, definitive management is required. With continued advancements in endourological techniques, ureteroscopy is frequently considered the first-line definitive treatment of obstructive ureteral calculi during pregnancy $[13,18]$. PCNL is not recommended in pregnancy due to need of general anesthesia, prone position and fluoroscopic radiation hazards.

Although ureteric stone occurrence during pregnancy is not very frequent, it still poses a challenge in diagnosis as well as treatment. There are several lacunae and confusions related with the diagnostic imaging, MET, reliability of ureteral stent/PCN insertions, safety of ureteroscopy and follow-up protocol during pregnancy.

Present review was carried out on carefully selected up-to-date articles, including those reporting on the diagnosis and management of ureteric stones during pregnancy. Aim of this review is to explain the use of various diagnostic and treatment modalities used in the management of ureteric stones during pregnancy based on a literature review and the authors' experience.

\section{Main text}

\subsection{Materials and methods}

A systematic review was performed of management of ureteric stone in pregnancy, with an attempt to stick to Preferred Reporting Items for Systematic Reviews and Meta-Analyses (PRISMA) guidelines. The literature review was performed using PubMed database in structured and comprehensive manner. We identified original articles of "ureteric stone in pregnancy," and the search was restricted to available literature in English language only. Inclusion criteria were articles published from starting to March 2020; special emphasis was laid on relevant articles reporting the diagnosis, management and outcomes of ureteric stone in pregnancy. Small case series, case reports, comments and editorials were excluded for part of this study. The search was conducted in PubMed database by the first author using the keywords: "ureteric stone," "ureterolithiasis," "ureteric," "stone," "ureteral calculi," "ureteral," "calculi" and "pregnancy." The search recognized 260 studies in total and was narrowed down to 111 studies after excluding duplicates and relevancy. On further screening of abstract, total 51 studies were included and nine articles were identified for full text eligibility into the study [19-27]. Two authors were involved in retrieving the information independently, and they finalized the inclusion of articles for this review. The likely shortcomings of a single database review system and selection bias are admitted.

\subsection{Evidence synthesis}

Management of ureteric stones in pregnancy is critical because of associated risks to mother and fetus $[9,28]$. Proper timely diagnosis and the best possible treatment without any harm are the key to manage such conditions, and the limiting factor is the inability to use the imaging modality (X-ray, CT scan) for diagnosis and side effects of traditional treatment methods during pregnancy. We opted to review the available literature on this issue and analyzed the nine studies. 


\subsection{Study population}

A total of nine studies on the management of ureteric stone in pregnancy were reviewed for this study (Fig. 1, Table 1).

\subsection{Diagnostic evaluation}

\subsubsection{History and physical examination}

Diagnosis of ureteric calculi in this patient population is difficult; a high index of suspicion is required. It is often misdiagnosed as appendicitis, diverticulitis and placental abruption. However in the included nine studies, none of the patients was misdiagnosed. Main clinical symptom of ureteric stone is colicky or dull aching pain with radiation to lower abdomen or labial region which is a presenting feature in 80 to $100 \%$ of the patients [29]. Other symptoms are nausea, vomiting, unexplained fever, recurrent urinary tract infections (UTI), hematuria and lower urinary tract symptoms (LUTS) like frequency and urgency [30]. In pregnancy, nausea and vomiting are very common because of progesterone [31]. In the included nine studies, 30.2\% (112/371) patients were having these symptoms. Some rare symptoms associated with pregnancy are pre-eclampsia and premature onset of labor [12]. In the included studies, seven patients (out of 371) developed premature onset of labor which was controlled by tocolytics.

On physical examination, tenderness on palpation can be seen and tachycardia may be present in UTI with fever patients. In the included nine studies, tenderness was reported in 3.8\% (14/371) patients. A past history of renal stone disease should also be sought because dilated ureters during pregnancy may allow passing renal stone into it. History of urolithiasis was present in $8.1 \%(30 / 371)$ patients in the included nine studies.

In this review included nine studies, total $74.4 \%$ $(276 / 371)$ patients were presented with colicky pain, LUTS in $11.6 \%$ (43/371), fever in $8.3 \%(31 / 371)$ and macroscopic hematuria in $4.9 \%(18 / 371)$ patients.

\subsubsection{Laboratory test}

Urinalysis is a primary test for these patients, and it should be examined for signs of active UTI or microscopic hematuria. Patient with pyuria and bacteriuria should be evaluated with urine culture and sensitivity test. Microscopic hematuria can be present in $95 \%$ to $100 \%$ of such cases [32]. Complete blood count, renal function test, serum electrolytes and serum calcium level should be checked. Metabolic evaluation should be considered after the completion of pregnancy because hormonal effect in pregnancy generally alters the accurate result [33, 34]. In the included eight studies, 48\% (144 patients of 301) were positive for microscopic hematuria, while one study [26] did not provide the data regarding laboratory test detail. Leukocyturia was seen in $11.6 \%$ $(35 / 301)$, and positive urine culture was in $12 \%(36 / 301)$. None of the included study performed metabolic workup during pregnancy.

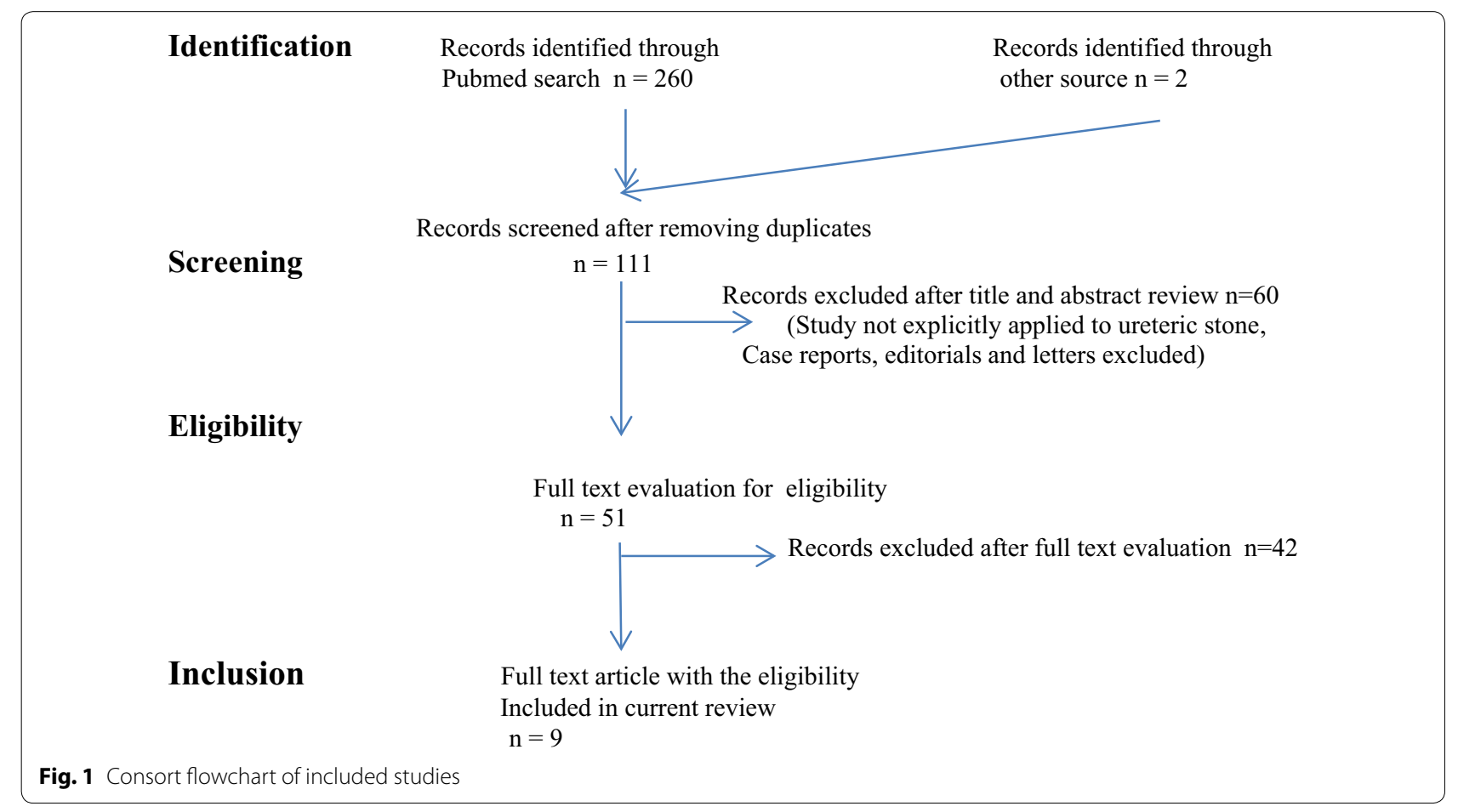


Table 1 Nine studies reporting management of ureteric stone in pregnancy were reviewed

\begin{tabular}{|c|c|c|c|c|c|c|c|c|}
\hline Study & $\begin{array}{l}\text { Design } \\
\text { of study }\end{array}$ & $\begin{array}{l}\text { Number } \\
\text { of patients }\end{array}$ & $\begin{array}{l}\text { Gestation } \\
\text { period } \\
\text { (weeks) }\end{array}$ & $\begin{array}{l}\text { Symptoms } \\
\text { and signs } \\
\text { at presentation }\end{array}$ & $\begin{array}{l}\text { Laboratory } \\
\text { results }\end{array}$ & $\begin{array}{l}\text { Diagnostic } \\
\text { modality }\end{array}$ & $\begin{array}{l}\text { Treatment } \\
\text { modality }\end{array}$ & Complications \\
\hline $\begin{array}{l}\text { LEMOS et al., } \\
2002 \text { [19] }\end{array}$ & $\begin{array}{l}\text { Prospective } \\
\text { study }\end{array}$ & 18 & 28 (median) & $\begin{array}{l}\text { Lumbar pain-14 } \\
\text { abdominal } \\
\text { pain-4 }\end{array}$ & $\begin{array}{l}\text { Microscopic } \\
\text { hematu- } \\
\text { ria-13, } \\
\text { Leukocyturia-8 } \\
\text { Urine cul- } \\
\text { ture + in } 4 \\
\text { RFT-normal } \\
\text { in all }\end{array}$ & $\begin{array}{l}\text { USG: } 12 \text { and } \\
\text { MRI: } 2\end{array}$ & $\begin{array}{l}\text { DJ stent: } 4 \\
\text { URS: } 14\end{array}$ & $\mathrm{Nil}$ \\
\hline $\begin{array}{l}\text { Elgamasy et al., } \\
2009 \text { [20] }\end{array}$ & Case series & 42 & 25.9 (mean) & $\begin{array}{l}\text { Colicky pain-15 } \\
\text { infection-10 } \\
\text { hematuria-9 } \\
\text { calculus anuria-1 }\end{array}$ & $\begin{array}{l}\text { Microscopic } \\
\text { hematuria-9 } \\
\text { Urine cul- } \\
\text { ture }+ \text { in } 4 \\
\text { RFT-deranged } \\
\text { in } 1 \text { patient }\end{array}$ & $\begin{array}{l}\text { USG:42 } \\
\text { Doppler } \\
\text { USG:42 }\end{array}$ & $\begin{array}{l}\text { Conservative: } \\
27 \\
\text { URS: } 15\end{array}$ & $\begin{array}{c}\text { Premature } \\
\text { labor: } 1\end{array}$ \\
\hline $\begin{array}{l}\text { Hoşcan et al., } \\
2012 \text { [21] }\end{array}$ & Retrospective & 57 & 26 (mean) & $\begin{array}{l}\text { Flank pain-51 } \\
\text { Fever-6 } \\
\text { Irritative void- } \\
\text { ing-11 }\end{array}$ & $\begin{array}{l}\text { Microscopic } \\
\text { hematu- } \\
\text { ria-40 } \\
\text { Urine cul- } \\
\text { ture + in } 6 \\
\text { RFT-Normal } \\
\text { in all }\end{array}$ & USG: 57 & $\begin{array}{l}\text { Conservative: } \\
23 \\
\text { DJ stent: } 5 \\
\text { URS: } 29\end{array}$ & $\begin{array}{l}\text { UTI: } 1 \\
\text { Premature } \\
\quad \text { uterine } \\
\text { contraction: } 1\end{array}$ \\
\hline $\begin{array}{l}\text { Abdel-Kader } \\
\text { et al., } 2013 \\
\text { [22] }\end{array}$ & Prospective & 23 & 25 (mean) & $\begin{array}{l}\text { Colicky pain-17 } \\
\text { Pain and fever-6 }\end{array}$ & $\begin{array}{l}\text { Urine cul- } \\
\text { ture + in } 6 \\
\text { RFT-Normal } \\
\text { in all }\end{array}$ & $\begin{array}{l}\text { USG: } 20 \text { and } \\
\text { MRI: } 3\end{array}$ & $\begin{array}{l}\text { DJ stent: } 6 \\
\text { URS: } 17\end{array}$ & Nil \\
\hline $\begin{array}{l}\text { Georgescu } \\
\text { et al., } 2014 \\
\text { [23] }\end{array}$ & Prospective & 54 & 9-35 (range) & $\begin{array}{l}\text { Flank pain-52 } \\
\text { Fever-4 } \\
\text { Irritative void- } \\
\quad \text { ing-14 }\end{array}$ & $\begin{array}{l}\text { Microscopic } \\
\text { hematu- } \\
\text { ria-40 } \\
\text { Leukocytu- } \\
\text { ria-18 } \\
\text { Urine cul- } \\
\text { ture+ in } 6 \\
\text { RFT-Normal } \\
\text { in all }\end{array}$ & $\begin{array}{l}\text { USG: } 52 \text { and } \\
\text { Limited IVP:2 }\end{array}$ & $\begin{array}{l}\text { DJ stent: } 9 \\
\text { PCN: } 1 \\
\text { Semirigid } \\
\text { URS:32 } \\
\text { Flexible URS: } \\
12\end{array}$ & $\begin{array}{l}\text { UTI:4 } \\
\text { Hematuria:1 }\end{array}$ \\
\hline $\begin{array}{c}\text { Adanur et al., } \\
2014 \text { [24] }\end{array}$ & Retrospective & 19 & 24.8 (mean) & $\begin{array}{l}\text { Colicky pain-14 } \\
\text { Fever-2 }\end{array}$ & $\begin{array}{l}\text { Microscopic } \\
\text { hematuria } \\
\text { and pyuria-9 } \\
\text { Urine cul- } \\
\text { ture + in } 4 \\
\text { RFT-Normal } \\
\text { in all }\end{array}$ & USG: 19 & URS: 19 & $\begin{array}{l}\text { Preterm uterine } \\
\text { contraction: } 1 \\
\text { UTI: } 1\end{array}$ \\
\hline $\begin{array}{l}\text { Teleb et al., } \\
2014 \text { [25] }\end{array}$ & Prospective & 43 & 26.6 (mean) & $\begin{array}{l}\text { Colicky pain-43 } \\
\text { Fever-10 }\end{array}$ & $\begin{array}{l}\text { Microscopic } \\
\text { hematu- } \\
\text { ria-24 } \\
\text { RFT-Normal } \\
\text { in all }\end{array}$ & USG: 43 & $\begin{array}{l}\text { DJ stent: } 22 \\
\text { URS: } 21\end{array}$ & UTI: 6 \\
\hline $\begin{array}{l}\text { Bayar et al., } \\
2015 \text { [26] }\end{array}$ & Retrospective & 70 & 23.4 (mean) & Colicky pain-70 & $\begin{array}{l}\text { RFT-Normal } \\
\text { in all }\end{array}$ & USG: 70 & $\begin{array}{l}\text { DJ stenting: } 29 \\
\text { URS: } 41\end{array}$ & $\begin{array}{l}\text { Ureteral lacera- } \\
\text { tion: } 3 \\
\text { Partial perfora- } \\
\text { tion } \\
\text { Of ureter: } 1 \\
\text { Pyelonephritis: } 2 \\
\text { Urosepsis: } 1 \\
\text { Premature uter- } \\
\text { ine contrac- } \\
\text { tion: } 2\end{array}$ \\
\hline
\end{tabular}


Table 1 (continued)

\begin{tabular}{|c|c|c|c|c|c|c|c|c|}
\hline Study & $\begin{array}{l}\text { Design } \\
\text { of study }\end{array}$ & $\begin{array}{l}\text { Number } \\
\text { of patients }\end{array}$ & $\begin{array}{l}\text { Gestation } \\
\text { period } \\
\text { (weeks) }\end{array}$ & $\begin{array}{l}\text { Symptoms } \\
\text { and signs } \\
\text { at presentation }\end{array}$ & $\begin{array}{l}\text { Laboratory } \\
\text { results }\end{array}$ & $\begin{array}{l}\text { Diagnostic } \\
\text { modality }\end{array}$ & $\begin{array}{l}\text { Treatment } \\
\text { modality }\end{array}$ & Complications \\
\hline $\begin{array}{l}\text { Abedi et al., } \\
2017 \text { [27] }\end{array}$ & Retrospective & 45 & 27.3 (mean) & $\begin{array}{l}\text { Colicky pain-36 } \\
\text { hematuria-9 } \\
\text { Fever-3 } \\
\text { Irritative void- } \\
\text { ing-18 }\end{array}$ & $\begin{array}{l}\text { Hematuria or } \\
\text { pyuria-9 } \\
\text { Urine cul- } \\
\text { ture+ in } 6 \\
\text { RFT-Normal } \\
\text { in all }\end{array}$ & USG: 45 & URS: 45 & $\begin{array}{l}\text { Premature uter- } \\
\text { ine contrac- } \\
\text { tion: } 2 \\
\text { UTI: } 2\end{array}$ \\
\hline $\begin{array}{l}\text { Total sum of } \\
\text { patients }\end{array}$ & & 371 & & & & & & \\
\hline
\end{tabular}

\subsubsection{Imaging for ureteric stones in pregnancy}

For the diagnosis of ureteric stone, proper evaluation requires various imaging modalities like ultrasonography (USG), X-ray of kidneys, ureters, and bladder (KUB) region, intravenous urography (IVU), computed tomography (CT) and magnetic resonance urography (MRU).

Although accurate diagnosis is important, it should not be at the cost of risky exposure to mother and fetus, so decision regarding imaging study should be well balanced between risks and benefits. Whenever ionizing radiation is used, it should follow the ALARA (as low as reasonably achievable) principle in pregnant females.

\subsubsection{Ultrasonography (USG)}

Abdominal USG is considered as a first-line imaging technique in cases of suspected ureteric calculi during pregnancy. It is easily available, not having any ionizing radiation exposure and is safe to mother and fetus. It gives details of the pelvicalyceal system, renal parenchyma, ureteric dilation and occasionally the calculus itself (Fig. 2). It may diagnose alternative pathology (bowel obstruction, appendicitis, placental abruption or inflammatory bowel disease) also [32].
The specificity of USG in detection of ureteric stone is around $90 \%$ which is good enough, but the sensitivity is quite low $(11-24 \%)$ especially in cases of middle ureteric calculi $[20,35]$. It is difficult to differentiate hydronephrosis due to obstructing stone from the physiological hydronephrosis of pregnancy [36]. In the included nine studies, USG was successful in diagnosis of ureteric calculi in $74.4 \%$ (276/371).

To improve USG imaging characteristics, a number of adjunct measurements have been utilized nowadays like transvaginal USG, Doppler USG with resistive index (RI) and urinary jets. Elgamasy A et al. [20] in their study used DUS with calculation of the intrarenal RI in both kidneys after conventional gray-scale US on 15 patients, and all showed increase in RI.

Transvaginal US assists in the detection of distal ureteral calculi obstruction and differentiates it from physiological hydronephrosis of pregnancy [37]. None of the included nine studies used this technique for stone diagnosis. The presence of hydroureter distal to the iliac vessels indicates obstruction as compared to physiological hydronephrosis of pregnancy [38]. Severe left-side hydroureteronephrosis also indicates pathological cause of

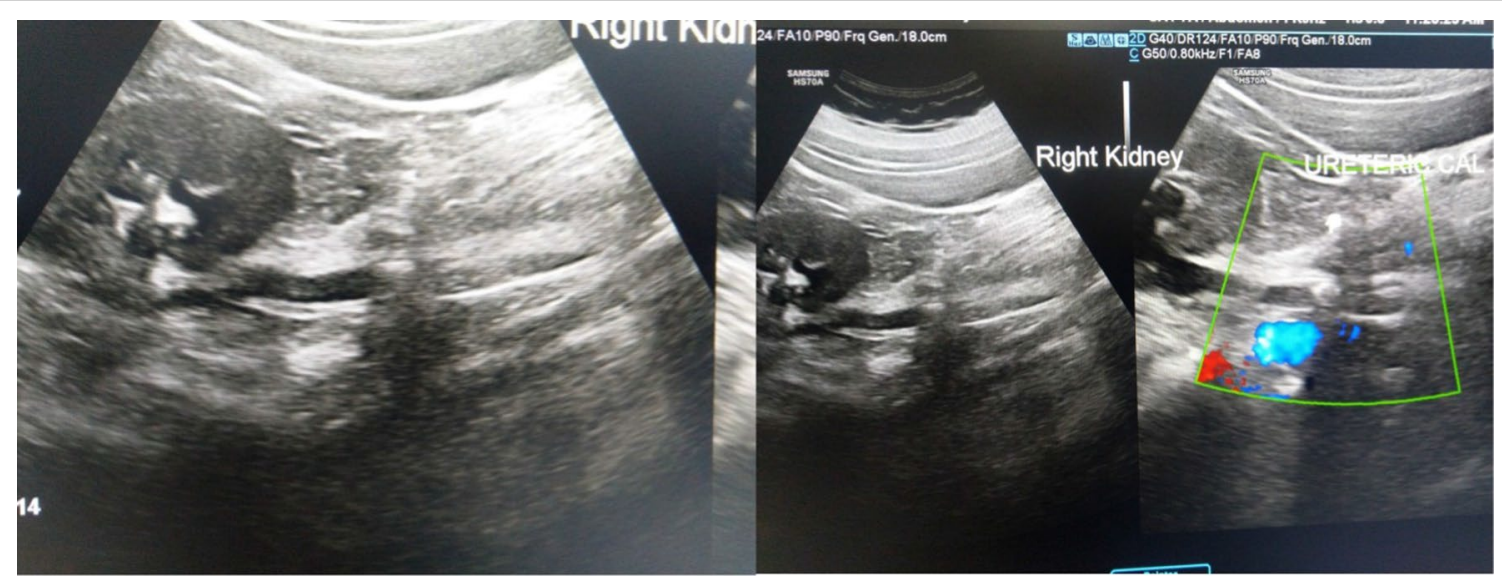

Fig. 2 Right ureteric stone detected by transabdominal ultrasound in pregnant women 
obstruction because commonly in pregnancy only mild to moderate dilation occurs on left-sided pelvicalyceal system [39].

Doppler-assisted measurement of the resistive index (RI) has been described to distinguish physiological hydronephrosis from pathologic obstruction. The intrarenal RI does not increase by the physiological hydronephrosis during pregnancy [40]. An elevated RI (>0.70) has been suggested as a marker of obstruction; however, it is not confirmatory and is nonspecific [41].

During Doppler US (DUS) in the first trimester, exposure time should be kept minimum and also the acoustic output at the lowest level to avoid high intensities which can pose of risk of potential damage to the fragile embryo [42]. Epidemiological studies in the human population have demonstrated, although controversial, that there might be an association between DUS exposure in pregnancy and some traits such as lower birth weight, left handedness and delayed speech [43, 44]. A recent study in mice furthermore suggested a potential correlation to autism, as pups which were exposed to intrauterine DUS showed significantly less interest in social interaction compared to the sham group [45].

The temperature elevation more than $1.5^{\circ} \mathrm{C}$ during Doppler is considered hazardous to the developing fetus [46]. Thermally induced bio-effects of DUS, which may even lead to teratogenesis, have already been suggested in a variety of studies, including in vitro and animal studies $[43,47-52]$.

The visualization of urinary jets usually indicates no obstructing calculi, and jet absence on the suspected side suggests the obstruction, with the sensitivity of $100 \%$ and specificity of $91 \%$ [53]. However, in $13 \%$ of pregnant patients jet may be absent normally and this is more commonly noted on the right side [54]. Asymmetry of the jets may be observed in ureteric calculi patients, but this is difficult to interpret. Visualization of urine jets is optimized by contralateral decubitus position and aggressive hydration before image collection. Ureteric jet was not evaluated in these included nine studies.

\subsubsection{Plain X-ray KUB and intravenous urography (IVU)}

Traditionally in the past, plain X-ray KUB and limited IVU (defined as three film study-using a scout film, a film at $30 \mathrm{~s}$ and one at $20 \mathrm{~min}$ ) have been used as secondline investigations for suspected ureteric stone in pregnancy (Fig. 3). A series of Stothers and Lee on IVU study in 17 patients showed delayed function on the affected side, and stones were diagnosed in 16 of the 17 cases [13]. In the included nine studies, only in one study limited IVU was used in two patients for confirmation of the diagnosis [23].
Although IVU gives important anatomic and functional information of renal units and is a sensitive and specific tool for the diagnosis of calculi in pregnant females, this modality was associated with the harmful radiation exposure, so gradually has been replaced by low-dose CT and MRI. Low-dose CT and MRI are more informative and comparatively safer in pregnancy, while conventional high-dose CT scan is contraindicated.

As per recent European Association of Urology (EAU) guidelines 2019, scientific societies and organizations agree on the safety of the diagnostic evaluation when US, $\mathrm{X}$-ray imaging and MRI use is indicated. A radiographic procedure should not be withheld from a pregnant woman if the procedure is clearly indicated and doing so will affect her medical care. It is generally recommended that an investigation resulting in an absorbed dose to the fetus of greater than $0.5 \mathrm{mGy}$ requires justification.

\subsubsection{Fetal radiation exposure by imaging techniques}

The prime concern is radiation exposure to fetus by various radiological investigations used in the pregnant patient especially in the first trimester because it is harmful and can lead to teratogenic effects, cell death, genetic mutations and carcinogenesis [55].

During the first trimester, a high dose of radiation (50-150 mGy) is associated with the risk of teratogenicity to $1-3 \%$ [56]. As per a study, relative risk of solid or hematologic malignancy by a prenatal X-ray exposure is about 2.4-fold higher as compared to non-exposure [57]. In this study, total 140 twins were evaluated (in which 31 were cases and 109 were controls). They found that twins in whom leukemia or other childhood cancer developed were twice as likely to have been exposed to $\mathrm{X}$-rays in utero as twins who were free of disease (relative risk, 2.4; 95 percent confidence interval -1.0 to 5.9 ). The gestational age at the time of radiation exposure to fetus is important factor, which determines the risk of teratogenicity. For induction of miscarriage or teratogenesis in the first trimester, the estimated threshold is $20 \mathrm{mGy}$, while in the second and third trimesters, it is $50 \mathrm{mGy}$ (cumulative exposure) [58]. In relation to carcinogenesis, there is no safe threshold of exposure because radiation is considered to have a stochastic effect on carcinogenesis. The in-utero exposure of $10 \mathrm{mGy}$ of radiation is associated with the risk of childhood cancer in 1/10,000 [58]. If the family is concerned about radiation-induced cancer, they should be reassured by the fact that approximately one extra case of cancer in this population of 10,000 would appear, if all 10,000 received $10 \mathrm{~m}$ Gy.

As per recent guidelines of American College of Obstetricians and Gynecologists (ACOG 2017), the radiation doses of $<50$ mGy in pregnancy are safe for the fetus 

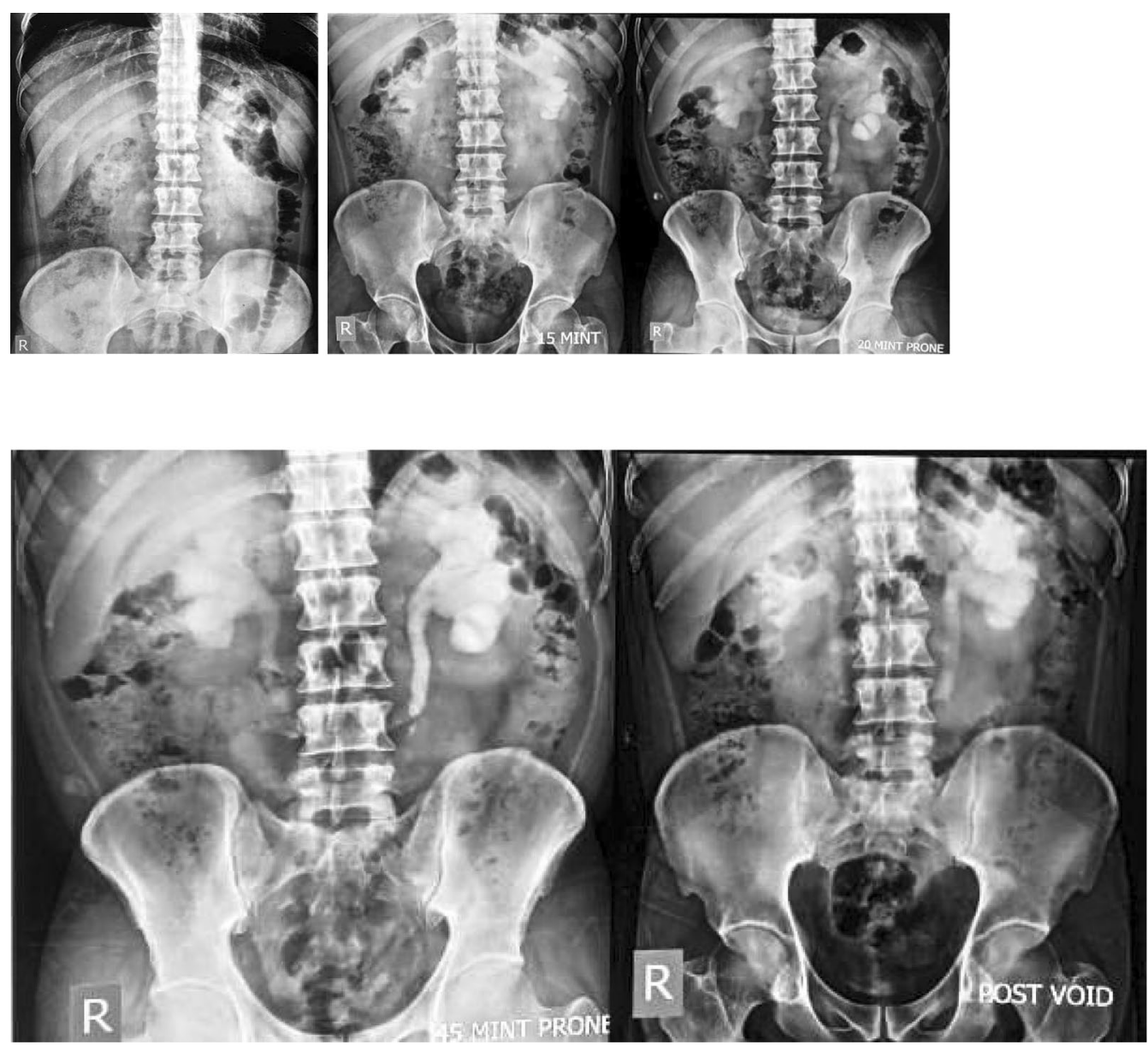

Fig. 3 Left ureteric stone detected by X-ray KUB and IVU in non-pregnant patient

without raising the risk of fetal anomalies or pregnancy loss [59]. In the included nine studies, none of the radiation-induced complications were reported in any child.

The approximate radiation dose to fetus by common imaging modalities applied to mother is listed in Table 2 [60].

\subsubsection{Low-dose computed tomography (CT)}

Conventional CT exposes the developing fetus to a higher dose of radiation (range 10 to $50 \mathrm{mGy}$ ) which can result in teratogenicity and childhood/fetal malignancy $[60,61]$. Therefore, such high-dose ionizing radiation examinations should be avoided and only be done in pregnancy when there is no diagnostic alternative and when the benefits outweigh the risks (Fig. 4) [62].
Table 2 Estimated fetal doses of radiation associated with maternal radiological procedures

\begin{tabular}{ll}
\hline Imaging study & $\begin{array}{l}\text { Radiation } \\
\text { dose } \\
\text { (mGy) }\end{array}$ \\
\hline USG & 0 \\
MRU & 0 \\
X-ray KUB & $1.4-4.2$ \\
IVU (3 film) & $1.7-10$ \\
CT (conventional) & $8-49$ \\
CT (low dose) & $\leq 7$ \\
MAG3 or DTPA & $0.2-4$ \\
\hline USG ultrasonography, & 0.4 magnetic resonance urography, X-ray KUB
\end{tabular}

USG ultrasonography, $M R U$ magnetic resonance urography, $X$-ray $K U B$ $\mathrm{X}$-ray of the kidneys, ureters and bladder, $I V U$ intravenous urogram, $C T$ computed tomography, DTPA diethylene triamine pentaacetic acid, MAG3 mercaptoacetyltriglycine 3 

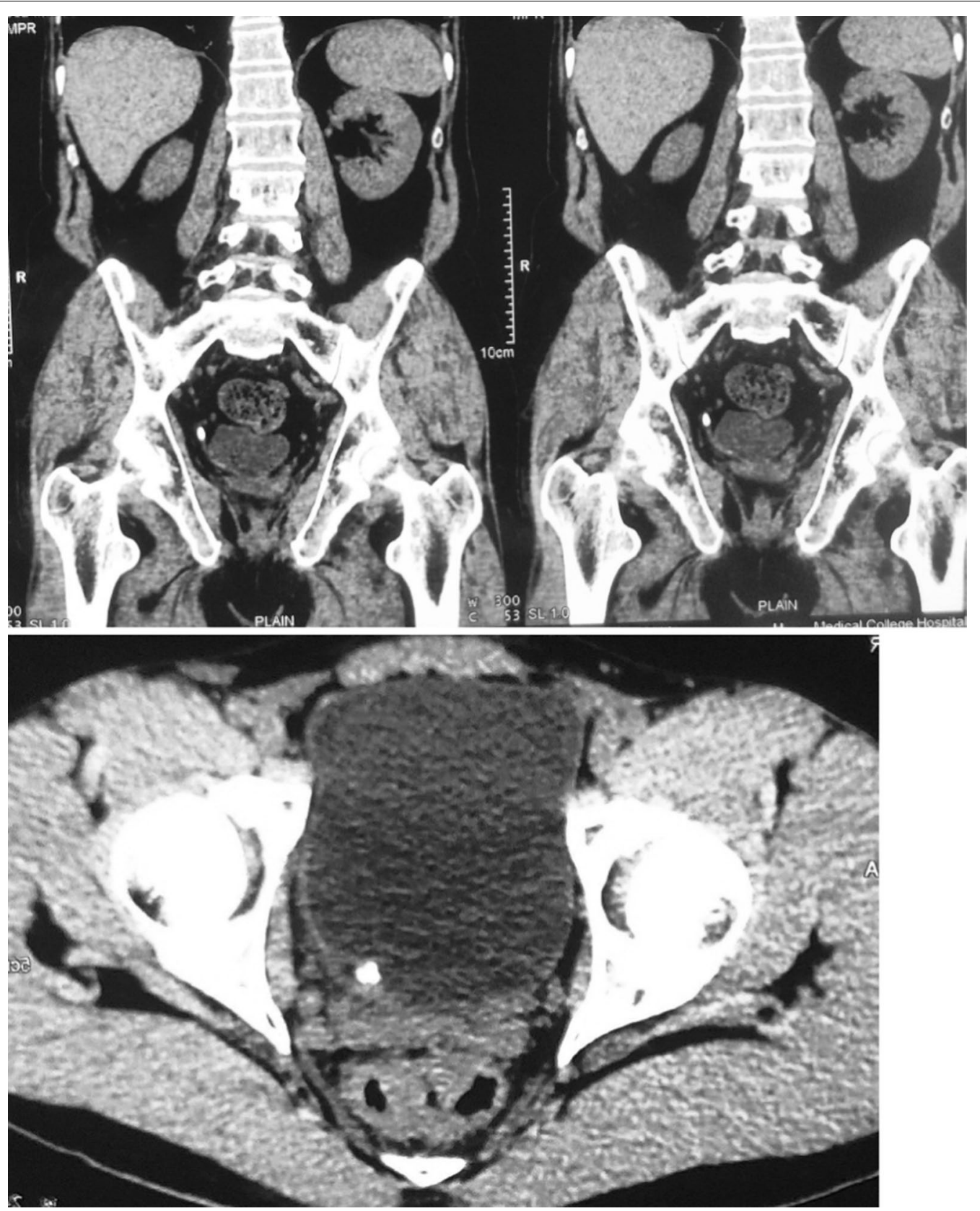

Fig. 4 Right lower ureteric stone detected by NCCT in non-pregnant patient

Low-dose CT is safe and highly accurate imaging technique and is preferable in patients with recurrent stone disease. For diagnosis of ureteric calculi, a low-dose CT scan with fetal radiation dose of $4 \mathrm{mGy}$ is highly sensitive (95\%) and specific (98\%) technique with good positive predictive value $(>95 \%)$. In this modality, body mass index of the patient is also important; it should be less than $30 \mathrm{~kg} / \mathrm{m}^{2}$ to maintain good sensitivity and specificity. Low-dose CT is increasing in popularity, but still not commonly used in the pregnancy [60,63]. Ultra-low-dose CT scan decreases the radiation dose below teratogenic threshold levels 
$(<1.9 \mathrm{mSv})$, so in this regard it is safer in pregnancy, but again theoretically, it is not completely acceptable due to stochastic effects [60].

According to one study on 20 pregnant females, the average radiation dose in low-dose CT was $7.1 \mathrm{mGy}$ [60]. After further refinement of this technique, radiation dose became very less ( $<2.5 \mathrm{mGy})$ and still work is going on this to reduce it as much as possible level [64].

As per EAU guidelines, in pregnant women, use lowdose computed tomography as a last-line option. None of the included nine studies used low-dose CT for diagnosis of ureteric stone in pregnancy.

Although longitudinal data support the relative safety of this technique during pregnancy, its use is limited due to persistent fears in radiologist and obstetricians.

ACOG currently endorses the use of low-dose CT scan during pregnancy for the proper diagnosis and management of significant medical problems, including urolithiasis [65]. The American Urological Association (AUA) also supports the use of low-dose CT (when ultrasound is non-diagnostic) as an imaging modality for females in the second or third trimester of pregnancy [66].

\subsubsection{Magnetic resonance urography (MRU)}

In pregnant patients, magnetic resonance imaging (MRI) is commonly used for the evaluation of acute abdominal pain. In MRI, there is no ionizing radiation exposure to fetus. The American College of Radiology (ACR) supports the use of this modality in pregnant patients in any trimester. Moreover, unknown bio-effects (during the period of organogenesis) exist, so extra caution is required when using MRI during the first trimester of pregnancy [67].
MRU without contrast is safe and effective; it is now considered the second-line investigation during pregnancy [68]. MRU has comparable accuracy to CT, and it can quickly acquire images of upper urinary tract without the use of intravenous contrast agents (Fig. 5).

MRU using T2-weighted "water" images is useful to identify the urinary system and ureters; it can differentiate dilatation due to physiological effects from dilatation related to calculi. For detection of small stones, a highresolution, thin-slice, highly $T 2$-weighted fast spin echo (FSE) sequence of MRU is helpful.

Half Fourier single-shot turbo spin echo (HASTE) MRU without contrast shows the calculus as a filling defect; assess the secondary characters of obstruction with information about other organ systems [69-71]. It is very fast with the acquisition time around 15 min [72]. In the diagnosis of acute ureteral obstruction during pregnancy, its sensitivity and specificity are good enough [73].

In a study of 24 pregnant women with symptomatic hydronephrosis, MRU had shown different appearances in pathologic obstruction and physiological hydronephrosis [72]. MRI is not accurate in ureteral calculi detection, but it shows some attributes which may help in obstructing calculi visualization: direct visualization of stones within a dilated ureter in the high signal of urine, the presence of dual constriction in ureter at the level of pelvic brim and ureterovesical junction (double-kink sign), an abrupt ending of the ureter, an "unusual" site of obstruction (vesicoureteric junction), perirenal fluid, renal enlargement, periureteral and perinephric edema [72].

In contrast, physiological hydronephrosis demonstrates a gradual, smooth tapering of the middle ureter due to
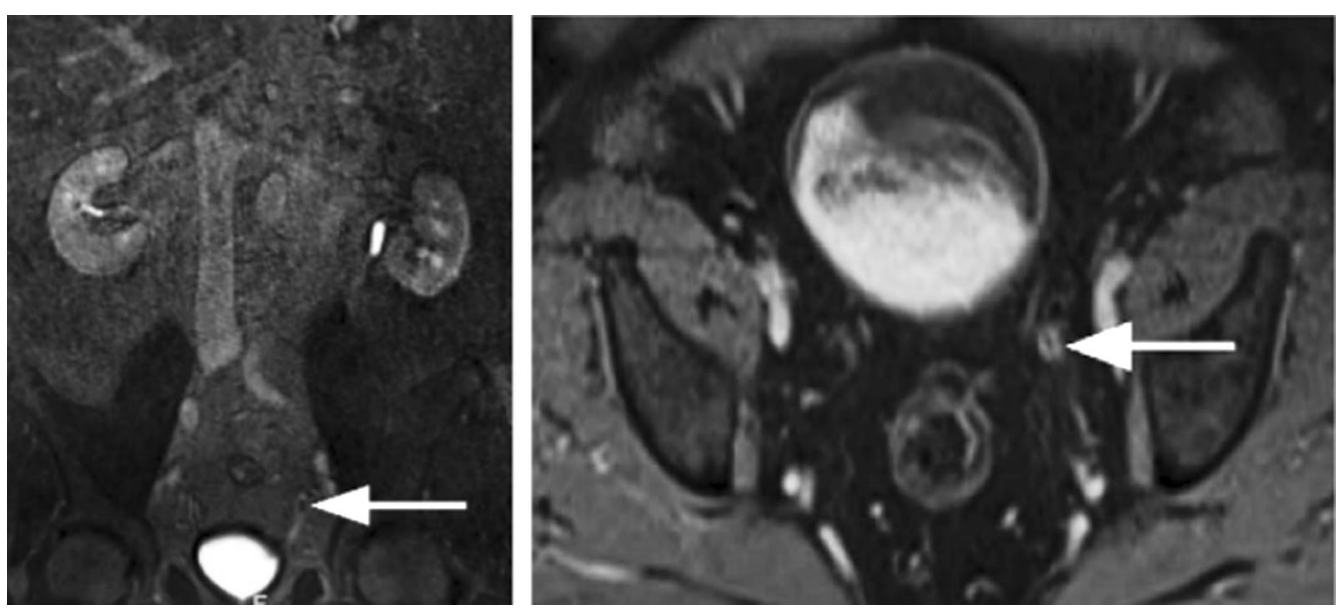

Fig. 5 Intraluminal filling defect (stone) in the distal left ureter detected by MRI 
extrinsic compression between the iliopsoas muscle and gravid uterus. In the included nine studies; Lemos [19] used MRI for the diagnosis of ureteric stone in two patients but did not locate the calculus in any of them; in another study of Abdel-Kader [22], MRI was required in three patients with middle ureteric stones to confirm ultrasound findings.

Limitations of MRU include relatively high cost, not easily available, not useful in patients with metallic implants, limited visualization of small calculi, time-consuming and artifacts mimicking as filling defects. Importantly, flow artifacts are typically centrally located and do not lie dependently, unlike the stone.

In pregnant patients, the diagnosis of ureteric stone still remains challenging. According to recent recommendations of AUA, USG is the first investigation in all pregnant patients suspected of colic, and if USG is not confirmatory, then MRU without contrast (gadolinium can cross the placenta) should be preferable in the first trimester and low-dose CT scan in the second or third trimesters [35, 66].

\subsection{Management overview}

After the diagnosis of ureteric calculus is made during pregnancy, a team work is required which involves multidisciplinary decision-making approach. Involvement of a urologist, obstetrician, radiologist, anesthesiologist and neonatologist is required due to the potential complications that can arise during management of these cases. Obstetrician and urologist together should outline a management plan with close follow-up and monitoring of patient. Initial choice is always a conservative approach (unless otherwise indicated) that uses hydration and analgesia for stone's passive expulsion.

There are some conditions that require immediate intervention like bilateral renal obstruction, obstruction in solitary kidney, uncontrolled pain and vomiting, active infection, deteriorating renal function due to progressive obstruction, poor access to urological care/equipment and imminent sign of pre-eclampsia and preterm labor [14]. The second trimester of pregnancy is preferable time to intervene because in this period risk to mother and fetus is minimal [74]. These interventions can be double J stenting or placement of PCN tube for diversion of urine in obstructed kidney and ureteroscopic stone retrieval. Other options of stone management like percutaneous nephrolithotomy (PCNL) and shock wave lithotripsy (SWL) use radiation, so they are contraindicated in pregnancy.

A management algorithm for the management of ureteric stone in pregnancy is given in Fig. 6.

\subsubsection{Expectant management}

Most pregnant females with symptomatic ureteric stones can be managed conservatively in the similar way of nonpregnant population because the rate of spontaneous passage of stones is high. With conservative therapy, up to $60-80 \%$ of patients pass their stones spontaneously without any complication [14, 29, 31]. Conservative treatment requires supervision by the urologist and obstetrician, and it comprises of analgesia, hydration (oral or intravenous), antiemetics and antibiotics if necessary.

This protocol is generally followed in the pregnant women who do not have any sign of infection, stone size $<1 \mathrm{~cm}$ and adequate pain relief by oral analgesics. Serial ultrasound should be done frequently during conservative treatment of such patients.

Aggressive fluid intake (oral/intravenous) is the main component of this treatment, which increases the urine flow and stone expulsion rate. Adverse effects of every drug on mother and fetus should be considered cautiously before prescribing them. Nonsteroidal antiinflammatory drugs (NSAIDs) are usually not preferred in pregnancy due to associated risk of oligohydramnios and pulmonary hypertension due to premature closure of the patent ductus arteriosus (PDA) in fetus [75]. Codeine is contraindicated in the first trimester due to teratogenic effects [76]. Narcotics are generally required and are considered safe, but prolonged use should be avoided [76]. Continuous epidural blockade (T11-L2) was also suggested as a beneficial option in management of stone during pregnancy [77].

Most of the patients (60-80\%) pass their stone during pregnancy. If patients are not able to pass the stone spontaneously during pregnancy, then about half of them will pass their stones after delivery [78]. According to some studies, the spontaneous passage rate of ureteric stone is higher during pregnancy as compared to non-pregnant status ( 81 vs. $47 \%$; $p<0.0001)$ that may be due to physiological ureteral dilation by progesterone effects [78-80]. Regarding these findings, some biases can be responsible such as general reluctance toward surgery, more time in trial for spontaneous passage and poor follow-up of patient. Another study by Burgess K.L. reported spontaneous passage rate of only $48 \%$ in this group [81].

In the included nine studies, Hoscan MB [21] reported $23 \%$ patients (13 out of 57 ) were managed conservatively. In these patients, stones were passed spontaneously with the use of analgesics, antispasmodics and hydration. In another study, Elgamasy [20] also reported that 64.3\% patients $(27 / 42)$ were managed successfully by conservative treatment. 
Pregnant patient with suspected ureteric colic

(flank pain, nausea, vomiting, unexplained fever, recurrent UTI,

haematuria, lower urinary tract symptoms like frequency and urgency)

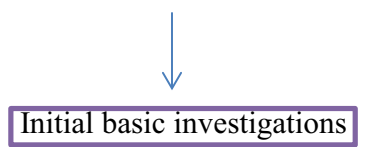

(urinalysis, urine culture and sensitivity, CBC, RFT, Serum electrolytes, PT/INR)
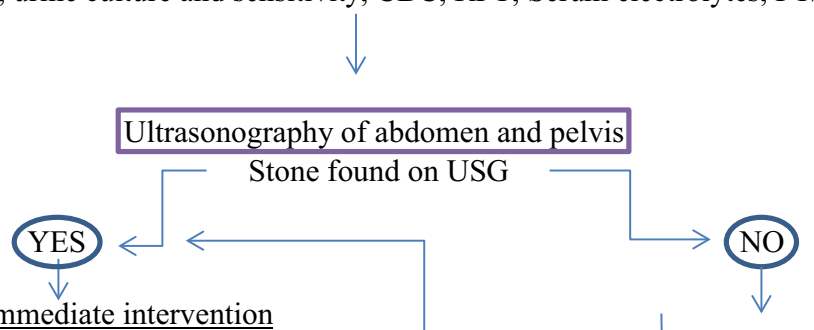

Patient requires immediate intervention

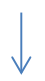

$\mathrm{NO}$

$\downarrow$

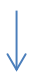

YES

(Indication for intervention + )

Expectant treatment

- hydration,

- pain control,

- serial USG

Medical expulsion therapy
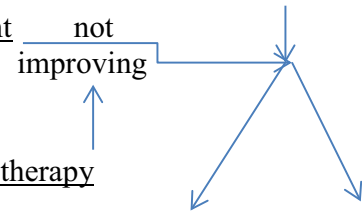

Temporizing options

- DJ stenting

- PCN insertion

Indications -

$\mathrm{B} / \mathrm{L}$ renal obstruction

Obstruction in solitary kidney

Large stone burden

Active infection

First trimester of pregnancy

Deteriorating renal function

Sign of pre-eclampsia/ preterm labor

Definitive management

- URS and lithotripsy

Indications -

No infection

Single $<1 \mathrm{~cm}$ stone

Second trimester pregnancy

Patient preference

Normal anatomy

$\underline{\text { MRU }}$

first trimester pregnancy

Low dose CT

-second/third trimester pregnancy<smiles>C1=CC=C1</smiles>

No stone found - symptoms due to non-urology cause -> manage accordingly - severe hydronephrosis ->

DJ stent/ PCN insertion

Fig. 6 Management algorithm for the management of ureteric stone in pregnancy

Size and location of the stone are two important factors that determine the rate of spontaneous expulsion. If the stones size is $<5 \mathrm{~mm}$, approximately $60-70 \%$ may be passed, and if the stones size is $5-10 \mathrm{~mm}, 40-50 \%$ will pass spontaneously within 4 weeks [82]. Another study of Andreoiu M and MacMahon reported that spontaneous expulsion rate is $44.1 \%$ and $27.3 \%$ for stones located in the vesicoureteric junction and proximal ureter or ureteropelvic junction, respectively [9].
Although conservative management is first-line therapy, it is critical to understand that when it has to stop and other intervention is required. The AUA guidelines also recommended conservative treatment initially for small calculi $(<1 \mathrm{~cm})$ in clinically fit patients. The preferred analgesic is small doses of morphine. Surgical management and pharmacologic strategies should be in coordination with obstetrician [83].

The recommended medications and their doses in pregnancy: 
For UTI

Ampicillin $500 \mathrm{mg}$ qid

Amoxicillin $250 \mathrm{mg}$ tid

Cephalexin $500 \mathrm{mg}$ qid

Cefaclor $500 \mathrm{mg}$ qid

Ceftriaxone $1 \mathrm{gm}$ i.v.

For analgesia, FDA recommends that where possible, the use of NSAIDs should be avoided during pregnancy. Although opioid can be used, risk of dependence (neuro-adaptation) and risk of withdrawal should be kept in mind.

\begin{tabular}{ll}
\hline For Analgesia & $\begin{array}{c}\text { Acetaminophen (paracetamol) } 500 \mathrm{mg} \\
\text { for mild pain is preferred. }\end{array}$ \\
\hline Morphine in small dose for severe pain \\
can be used. \\
Metoclopramide $5-10 \mathrm{mg}$ orally before \\
food is safe in pregnancy, \\
Antacids - pantoprazole in 20/40 mg.
\end{tabular}

Fluids-I.V. fluids can be used judiciously if patient is dehydrated. Normal saline or other I.V. fluids can be given according to the patient's condition and investigations.

\subsubsection{Medical expulsive therapy (MET)}

When conservative treatment fails, then medical expulsive therapy is used as an effort to trial of spontaneous passage of ureteric stone [84, 85]. The alpha blockers and calcium channel blockers are classified as Category $B$ drugs in pregnancy and are often used without any adverse effects. Calcium channel blocker is safer drug which is commonly used during pregnancy for the management of preterm labor and gestational hypertension [86]. Both alpha blockers and calcium channel blockers inhibit the peristaltic activity of ureter which facilitates stone expulsion. They may also help in decreasing the colic episodes, analgesic requirements and hospital admissions. The suggested dose of nifedipine for expulsive therapy $(20-30 \mathrm{mg})$ is not notably differing from that used for tocolysis.

As per recent retrospective cohort study, stone expulsion rate was improved by $24 \%$ with the use of tamsulosin without any adverse fetal or maternal outcomes [87]. As per recent email survey study with 565 respondents, the use of MET was $97.6 \%$ in general and $44.3 \%$ in pregnancy [88]. Although these recent studies are promising, further studies are warranted to support the use of MET in pregnancy. The recent AUA guideline supports that if MET is being advised in pregnancy, the patient should be warned that usage of these drugs in pregnancy is not well documented and they are being utilized for an off-label purpose [83].
In the included nine studies, Hoscan $\mathrm{MB}$ [21] reported $17.5 \%$ patients ( 10 out of 57 ) were managed symptomatically by MET successfully with the use of analgesics, antispasmodics and fluids.

\subsubsection{Indications for intervention}

The common consensus is to avoid the invasive treatment during pregnancy especially in the first trimester (risk of miscarriage is more) and the third trimester (preterm labor can be induced). Several authors have reported that in pregnancy the second trimester is the preferred period for non-obstetrical surgery in terms of safety and mater$\mathrm{nal} /$ fetal perinatal complications [74, 89-91].

Indications for intervention are same as general population that include failure of conservative treatment, unresolved symptoms, progressive hydronephrosis, urinary tract infection, sepsis, obstruction of a solitary kidney, bilateral obstruction, progressive renal impairment, poor access to urological care/equipment or complications related with pregnancy such as pre-eclampsia and preterm labor [14]. Decision of surgical intervention during pregnancy should be carefully planned with active involvement of experienced obstetrician and perinatologist.

\subsubsection{Options for intervention}

Approximately $20-30 \%$ of patients with ureteral calculi during pregnancy will ultimately require active treatment [23]. Active treatment can be subdivided into temporary drainage and definitive stone management. Temporary drainage can be achieved by either double J ureteral (DJ) stent placement or by PCN drainage, while definitive stone management can be done by ureteroscopy and lithotripsy.

\subsubsection{Temporizing options}

Temporary drainage is reasonable in the condition of failure of conservative treatment, complex anatomy, large stone burden, transplanted kidney, presentation very early or very late in the pregnancy, obstetric concerns or complications, active UTI and contraindications to definitive stone management [83, 92].

Advantages of temporizing treatments include less invasiveness, quickness, possibility to be done under local anesthesia, without radiation exposure, decrease in the pain, effectiveness in relieving obstruction and protection of renal functions [93]. Ureteral stents and PCN drainage both are safe and effective in pregnancy. During the decision of DJ stenting or placing PCN tube, stage of pregnancy, patient preference and tolerability should be considered. 
Disadvantages of temporary drainage include frequent exchange, multiple procedures, expensive, not well tolerated, dislodgement, migration, risk of urinary infection and that during each exchange, it subjects a risk on the pregnancy and it is not a definitive treatment, requires surgery in postpartum period. Other rare pitfalls include hematuria, premature delivery and sepsis [94].

\subsubsection{Stent}

Ureteral stents can be placed under local anesthesia or intravenous sedation. During the second or third trimesters of pregnancy, it can be placed with limited fluoroscopy. Ultrasound guidance may also be used for DJ stent insertion $[95,96]$. There is no need for an external urinary collection device with DJ stent.

A stent may be associated with the pain, poor tolerance, encrustation, bacterial colonization with risk of ascending UTI and decrease in quality of life. Stent migration occurs more frequently during pregnancy due to physiological hydronephrosis. It requires exchange in every 4-6 weeks due to high incidence of encrustation secondary to the metabolic changes in urinary chemistry that occur during pregnancy, such as hypercalciuria and hyperuricosuria $[18,95]$. The prolonged stenting may be associated with increased risk of bacteriuria, urinary tract infection and potential obstruction [95]. Antibiotics should be started whenever UTI is diagnosed with indwelling stent. In patients with high risk of preterm labor, the PCN placement is preferred option than DJ stenting [97].

According to a study, 7 out of 15 pregnant females with DJ stents required early induction secondary to stent intolerance [98]. The efficacy and safety of alpha blockers and antimuscarinics are not proven in pregnancy, so they should be used with caution to reduce stent-related lower urinary tract symptoms [99]. In the included nine studies, $20.2 \%$ (75 of 371 ) patients were managed successfully by $\mathrm{DJ}$ stent insertion.

\subsubsection{Percutaneous nephrostomy (PCN)}

Sepsis and pyonephrosis are the main indications for PCN, which provides immediate drainage for pus and samples for urine culture [100]. Renal drainage requirement in the first trimester and large stone burden are other conditions where PCN is preferred [95].

Main advantages of PCN tube are that it can be performed under local anesthesia with ultrasound guidance, has high success rate and is safe in pregnancy. Some other advantages are avoidance of ureteric manipulation so decreased risk of infection spread or ureteric injury, option of different sizes of drainage tube placement, possibility to be used for future access in percutaneous treatment of stones after birth and that it is more cost effective than DJ stent.
PCN drainage has several disadvantages such as tube dislodgement, need to carry external collecting bag, tube obstruction by debris, more pain symptoms, infection, bleeding and need for periodic changes. Placement of PCN tube is technically difficult in the third trimester and is preferred as a technique of choice for pregnancies of $\leq 22$ weeks [97].

In the included nine studies, Georgescu D [23] reported one of the patient out of 54 required $\mathrm{PCN}$ insertion for management.

\subsubsection{Stent versus percutaneous nephrostomy}

Stent versus nephrostomy tube which should be preferred is always a subject of debate. Both have welldefined advantages and disadvantages and are equally effective for decompressing the urinary tract. With regard to infection, a study has shown them to be equivalent [100]. Recent findings propose that both the procedures are equivalent in terms of patients outcomes also [101]. So, it is finally the clinical scenario, resource availability, surgeons and patients preference which make the decision among these two procedures.

\subsection{Overview of definitive stone management}

In the past, pregnant women with ureteric stone were managed by temporizing measures until delivery but gradually with the advancement in the instruments design and other technology; now, many gravid patients are managed by definitive treatment. Definitive stone management modalities include ureteroscopy, PCNL and SWL. The last two modalities are not used in the pregnant patients [80].

In contrast to temporizing procedures, definitive stone management eliminates the need for recurrent interventions (such as device exchange) and has similar complication rates [97]. Definitive stone management in the pregnancy requires collaborative team work that includes experienced urologist, obstetrician, anesthetist and neonatologist [102].

\subsubsection{Ureteroscopic stone removal (URS)}

Technological advancements such as the development of smaller size semirigid or flexible ureteroscope, advanced visualization, improved deflection, better fiber optics, refinement in the design of retrieval baskets, availability of lasers and advanced obstetrics care with improved monitoring technology have enabled the URS as a preferred first-line option for definitive management of ureteric stone in pregnancy [13].

URS is known to be safe and effective option in pregnancy since long time [103]. During the second and third trimesters of pregnancy in properly selected patients, it is feasible and safe with high stone clearance rates and low 
complication rates. Risks of anesthesia are more in the first trimester, so it is avoided in this period [74].

Indications for URS include conservative treatment failure or patient preference. Contraindications to URS include infection or sepsis, abnormal anatomy, large volume/multiple stones, obstetrical complications and insufficient urological, obstetric or anesthetic resources [80]. Ureteric dilatation is not needed because of already dilated ureters in pregnancy. Usually, URS is performed with fluoroscopic guidance in non-pregnant patients, but this strategy can be harmful in pregnancy. To reduce or eliminate fluoroscopy exposure in pregnancy, several modifications have developed such as use of pulsed fluoroscopy in low dose, lead shielding of the patient's pelvis, positioning of $\mathrm{C}$-arm image source below the patient and image coning to include only the renal area, ureteroscope path visualization by endoscopically or ultrasound-guided ureteroscopy $[78,104]$.

A retrospective study at five institutions on 46 gravid patients for the post-ureteroscopy obstetric outcomes assessment found two complications with overall obstetric complication rate of 4.3\% [102]. Even the similar complication rates were reported by other studies also, the managing team should be more vigilant because of potential risk to the developing fetus. According to the ACOG guidelines, any non-urgent surgeries such as ureteroscopic stone removal to be performed in the second trimester of pregnancy to decrease the risk of preterm contractions and spontaneous abortion [105].

Another consideration favoring URS is its low cost. As per a study of Wymer and colleagues, ureteroscopy was found to be less costly and more effective as compared to serial DJ stenting, especially during early pregnancy [106].

Many retrospective case series with URS in pregnancy with ureteric stone have shown stone free rates in the range of $63-93 \%$ [19, 20, 93, 107-109]. Ureteroscopic techniques for stone management varies and involves a combination of laser or pneumatic lithotripsy, different type of forceps and basket retrieval. In most case series after stone retrieval, a DJ stent was kept (50-100\%) to decrease the risk of obstructive complications $[20,109]$.

There are not many evidences in support of optimal intracorporeal lithotripter to use in gravid patients. Pneumatic lithotripters and holmium: YAG lasers are perceived to be safe and are currently recommended methods for intracorporeal stone fragmentation during pregnancy $[93,108]$. Holmium: YAG laser has little periureteral thermal effects and does not result in energy transmission to the fetus. During pregnancy, electrohydraulic lithotripter due to very high peak pressure raises tension throughout the uterine wall and may stimulate uterine contractions. Ultrasonic lithotripter produces high-frequency sound (acoustic wave with a frequency of $23-25 \mathrm{kHz}$ ), and there is also a high level of noise, imperceptible to the human ear, which can reach levels of $98 \mathrm{~dB}$ which may adversely affect fetal ear development (theoretically), so they should be avoided $[108,110]$.

During URS in pregnancy, position of patient should be kept in the lithotomy with additionally right side of the abdomen slightly lifted up to reduce the compression of the inferior vena cava by uterus. After the procedure a DJ stent should be kept to decrease the complications [97]. Fetal monitoring should be performed throughout the procedure and after completion [78].

In the included nine studies, $66.03 \%$ patients $(245 / 371)$ were managed by URS in pregnancy successfully, in which flexible URS was used in 12 patients.

The complications reported in various series are minimal, and these included UTIs (most common), ureteral perforation, preterm labor and delivery $(0-1 \%)[108,109$, $111,112]$. For occurrence of an obstetric complication in URS during pregnancy, there were no significant risk factors found in some studies $[13,102]$. The action of laser on uric acid stones may produce cyanide theoretically, but this has not been reported, as irrigation fluid likely removes any cyanide which has formed [113].

As per a study, early interventions are more likely to achieve better outcomes because it reduces the risk of UTI, sepsis and other complications. Low pressure perfusion and short operation times are recommended for the best outcome [114]. Experience of surgeon, patient selection, available resources and multi-disciplinary approach are critical for good outcome.

\subsubsection{Percutaneous nephrolithotomy (PCNL)}

PCNL is contraindicated in pregnancy due to commonly utilized prone position and significant fluoroscopy exposure. If PCNL is required in a pregnant patient, it is best performed after the delivery. There are few case reports available in the literature with modified PCNL during pregnancy in the supine position with USG guidance and minimal fluoroscopic use. Although they have reported good outcomes, nevertheless it should be avoided whenever possible in pregnant female $[115,116]$. None of the included nine studies reported experience with PCNL in this population.

\subsubsection{Extracorporeal shock wave lithotripsy (ESWL)}

ESWL is contraindicated in pregnancy because of risk of fetal damage. ESWL is a noninvasive method for stone fragmentation and is the preferred treatment for simple stones $<1 \mathrm{~cm}$, in the kidney and upper ureter [82]. It uses high-intensity ultrasonic pulses to break the stone.

In the literature, there are few animal studies in which the effects of SWL on fetal development were assessed 
[113, 117-119]. They showed that SWL is associated with low birth weight (in early gestation) and intra-parenchymal hemorrhages in lungs, liver and kidney tissues $[113,119]$. ESWL in pregnancy may result in miscarriage, intrauterine growth retardation, congenital malformations and placental displacement [120]. Any gravid woman with stones should never be exposed to the risks associated with SWL. Although there are few case reports available on successful delivery of healthy babies (without any malformations or chromosome anomalies) in women who underwent ultrasound-guided SWL inadvertently, however it does not justify the use of SWL during pregnancy without further research [121]. None of the included nine studies reported experience with ESWL in this population.

\subsubsection{Laparoscopic/open surgery}

In some selected cases, it remains the only option. Surgery under general anesthesia during the first and last trimester may be associated with birth defects, prematurity, delayed intrauterine growth and fetal death. In first, second and third trimesters, the reported preterm birth rate is $6.5 \%, 8.6 \%$ and $11.9 \%$, respectively [30]. The laparoscopic surgery may be a better option than open surgery in terms of hospital stay and cosmesis. When all other options fail in a gravid patient with severe symptoms, then only laparoscopic/open surgery is to be considered; otherwise, it is best avoided. None of the included nine studies reported any experience with laparoscopic/open surgery in this population.

Overall in the included nine studies with 371 patients, total success rate for conservative treatment was 13.5\%, for temporary drainage (DJ and PCN) was $20.5 \%$ and for ureteroscopy was $66.04 \%$.

\subsubsection{Metabolic workup}

A detailed metabolic workup is helpful for the gravid patient with ureteric stone, but it should be performed only after the recovery of patient following child birth [122]. As per EAU guidelines, once urinary parameters have been normalized, it is sufficient to perform 24-h urine evaluation. The EAU panel realizes that on this issue there is only very limited published evidence and the exact timing cannot be defined. A competent urologist or nephrologist can do the relevant investigations for the metabolic evaluation of patients.

\subsubsection{Perinatal effects of ureteric stone in pregnancy}

The possibility of perinatal complications may increase by symptomatic ureteric stones. There are conflicting evidences in the literature $[123,124]$. Banhidy et al. did not find any significant association between the incidence of low birth weight, preterm birth or fetal abnormalities and stones during pregnancy [123]. On the other hand, some studies suggested that stones in gravid women may increase the incidence of pre-eclampsia, caesarean section rates, low birth weight babies and preterm births $[10,123,124]$.

\section{Conclusion}

During pregnancy, ureteric stone is a diagnostic and therapeutic challenge. It increases the morbidity for mother and fetus by increasing the risk of obstetric complications.

Ultrasound remains a mainstay of diagnostic imaging, and MRU is a second-line investigation in such patients. Conservative treatment with MET should be an initial management option for majority of the patients. Depending on the clinical scenario, insertion of PCN tube or DJ stent may be considered in some patients initially. If a patient requires intervention due to failure of other therapies, then ureteroscopy with holmium laser or intracorporeal pneumatic lithotripsy is a safe and effective first-line definitive therapeutic option.

For every pregnant patient, the available options for diagnosis and treatment should be evaluated with a careful assessment of the risks and benefits. A thoughtful approach that takes into account the individual clinical variables, gestational age of the pregnancy, available resources, patients and surgeons preferences should be the intent in each case and preserving the maternal-fetal well-being should be the main target. Ultimately, a multi-disciplinary approach involving experienced urologists, obstetricians, neonatologists, radiologists and anesthesiologists is critical to maximizing safe outcomes for mother and child.

\section{Abbreviations}

MET: Medical expulsive therapy; DJ: Double J; PCN: Percutaneous nephrostomy; PCNL: Percutaneous nephrolithotomy; UTI: Urinary tract infection; USG: Ultrasonography; CT: Computed tomography; MRU: Magnetic resonance imaging; Rl: Resistive index; SWL: Shock wave lithotripsy; URS: Ureteroscopy.

\section{Acknowledgements}

The authors would like to thank all co-authors who provided their clinical experience and knowledge.

\section{Authors' contributions}

APST, SS and VR contributed to data analysis. APST, AC and PP helped with drafting of manuscript. APST, VS, VR, AC, PP, SS and SP contributed to critical revision of the manuscript. All authors have read and approved the final manuscript.

Funding

Nil. 


\section{Availability of data and materials}

The datasets used and analyzed during the current study are already provided in chart.

\section{Ethics approval and consent to participate}

Not applicable because it was a review article.

\section{Consent for publication}

Not applicable.

\section{Competing interests}

The authors declare that they have no competing interests.

\begin{abstract}
Author details
${ }^{1}$ Department of Urology, Super Speciality Hospital, Netaji Subhash Chandra Bose Medical College, Jabalpur, M.P., India. ${ }^{2}$ Department of Urology, Super Speciality Hospital, Shyam Shah Medical College, Rewa, M.P., India. ${ }^{3}$ Department of Urology, Super Speciality Block, Government Medical College Thiruvananthapuram, Thiruvananthapuram, Kerala, India. ${ }^{4}$ Triveni Institute of Dental Sciences Hospital and Research Centre Bilaspur, Bilaspur, C.G., India.
\end{abstract}

Received: 11 May 2020 Accepted: 16 September 2020

Published online: 11 November 2020

\section{References}

1. Gorton E, Whitfield HN (1997) Renal calculi in pregnancy. Br J Urol 80(Suppl 1):4-9

2. Maikranz P, Coe FL, Parks JH, Lindheimer MD (1987) Nephrolithiasis and gestation. Baillieres Clin Obstet Gynaecol 1:909-919

3. Loughlin KR (1994) Management of urologic problems during pregnancy. Urology 44:159-169

4. Drago JR, Rohner TJ Jr, Chez RA (1982) Management of urinary calculi in pregnancy. Urology 20:578-581

5. Cherianchan D, Arianayagam M, Rashid P (2008) Symptomatic urinary stone disease in pregnancy. Aust N Z J Obstet Gynaecol 48:34-39

6. Peake SL, Roxburgh HB, Langlois SL (1983) Ultrasonic assessment of hydronephrosis of pregnancy. Radiology 146:167-170

7. Patel SJ, Reede DL, Katz DS, Subramaniam R, Amorosa JK (2007) Imaging the pregnant patient for nonobstetric conditions: algorithms and radiation dose considerations. Radiographics 27:1705-1722

8. Ashley ER, Shelly HN, James EL, Brian RM (2008) Kidney stones during pregnancy: an investigation into stone composition. Urol Res 36:99-104

9. Andreoiu M, MacMahon R (2009) Renal colic in pregnancy: lithiasis or physiological hydronephrosis? Urology 74:757-761

10. Kroovand RL (1996) Stones in pregnancy. In: Coe FL, Favus MJ, Pak CYC, Parks JH, Preminger GM (eds) Kidney stones: medical and surgica management. Lippincott-Raven, Philadelphia, pp 1059-1064

11. Rosenberg E, Sergienko R, Abu-Ghanem S et al (2011) Nephrolithiasis during pregnancy: characteristics, complications, and pregnancy outcome. World J Urol 29:743-747

12. Swartz MA, Lydon-Rochelle MT, Simon D et al (2007) Admission for nephrolithiasis in pregnancy and risk of adverse birth outcomes. Obstet Gynecol 109:1099-1104

13. Lifshitz DA, Lingeman JE et al (2002) Ureteroscopy as a first line intervention for ureteral calculi in pregnancy. J Endourol 16:19-22

14. Stothers L, Lee LM (1992) Renal colic in pregnancy. J Urol 148(5):1383-1387

15. Abdel-Gawad M, Kadasne R, Anjikar C, Elsobky E (2014) Value of color Doppler ultrasound, kub and urinalysis in diagnosis of renal colic due to ureteral stones. Int Braz J Urol 40(4):513-519

16. Yen P, Bailly G, Pringle C, Barnes D (2014) Dual-energy KUB radiographic examination for the detection of renal calculus. Acad Radiol 21(8):1035-1037

17. Juan YS, Wu WJ, Chuang SM, Wang CJ, Shen JT, Long CY et al (2007) Management of symptomatic urolithiasis during pregnancy. Kaohsiung J Med Sci 23:241-246
18. Kavoussi L, Albata D, Basler J, Apte S, Clayman R (1992) Percutaneous management of urolithiasis during pregnancy. J Urol 148:1069-1074

19. Lemos GC, El Hayek OR, Apezzato M (2002) Rigid ureteroscopy for diagnosis and treatment of ureteral calculi during pregnancy. Int Braz J Urol 28:311-316

20. Elgamasy A, Elsherif A (2010) Use of Doppler ultrasonography and rigid ureteroscopy for managing symptomatic ureteric stones during pregnancy. BJU Int 106(2):262-266

21. Hoşcan MB, Ekinci M, Tunçkıran A, Oksay T, Özorak A, Özkardeş H (2012) Management of symptomatic ureteral calculi complicating pregnancy. Urology 80(5):1011-1014

22. Abdel-Kader MS, Tamam AA, Elderwy AA, Gad M, El-Gamal MA, Kurkar A et al (2013) Management of symptomatic ureteral calculi during pregnancy: experience of 23 cases. Urol Ann 5(4):241-244

23. Georgescu D, Mulțescu R, Geavlete B, Geavlete P, Chiuțu L (2014) Ureteroscopy: first-line treatment alternative in ureteral calculi during pregnancy? Chirurgia (Bucur) 109(2):229-232

24. Adanur S, Ziypak T, Bedir F, Yapanoglu T, Aydın HR, Yılmaz M et al (2014) Ureteroscopy and holmium laser lithotripsy: is this procedure safe in pregnant women with ureteral stones at different locations? Arch Ital Urol Androl 86(2):86-89

25. Teleb M, Ragab A, Dawod T, Elgalaly H, Elsayed E, Sakr A et al (2014) Definitive ureteroscopy and intracorporeal lithotripsy in treatment of ureteral calculi during pregnancy. Arab J Urol 12(4):299-303

26. Bayar G, Bozkurt Y, Acinikli H, Dagguli M, Cakmak S, Nuri Bodakci M et al (2015) Which treatment method should be used in pregnant patients with ureteral calculi? Two center comparative study. Arch Esp Urol 68(4):435-440

27. Abedi AR, Allameh F, Razzaghi MR, Fadavi B, Qashqai H, Najafi S et al (2017) The efficacy and safety of laser lithotripsy in pregnancy. J Lasers Med Sci 8(2):84-87

28. Pais VM Jr, Payton AL, LaGrange CA (2007) Urolithiasis in pregnancy. Urol Clin North Am 34(1):43-52

29. Lewis DF, Robichaux AG III, Jaekle RK et al (2003) Urolithiasis in preg nancy. Diagnosis, management and pregnancy outcome. J Reprod Med 48:28-32

30. Biyani CS, Joyce AD (2002) Urolithiasis in pregnancy. I: pathophysiology, fetal considerations and diagnosis. BJU Int 89:811-818

31. Parulkar BG, Hopkins TB, Wollin MR, Howard PJ, Lal A (1998) Renal colic during pregnancy: a case for conservative treatment. J Urol 159:365-368

32. Jones WA, Correa RJ Jr, Ansell JS (1979) Urolithiasis associated with pregnancy. J Urol 122:333-335

33. Srirangam SJ, Hickerton B, Van Cleyenbreugel B (2008) Management of urinary calculi in pregnancy: a review. J Endourol 22:867-875

34. Lipkin ME, Ferrandino MN, Preminger GM (2016) Evaluation and medical management of urinary lithiasis. Campbell walsh urology, 11 th edn. Elsevier, Philadelphia, p 1200-1234.e7

35. Teichman JM (2004) Clinical practice. Acute renal colic from ureteral calculus. N Engl J Med. 350:684-693

36. Marchant DJ (1972) Effects of pregnancy and progestational agents on the urinary tract. Am J Obstet Gynecol 112:487-501

37. Yang JM, Yang SH, Huang WC (2005) Transvaginal sonography in the assessment of distal ureteral calculi. Ultrasound Obstet Gynecol 26(6):658-662

38. MacNeily AE, Goldenberg SL, Allen GJ, Ajzen SA, Cooperberg PL (1991) Sonographic visualization of the ureter in pregnancy. J Urol 146(2):298-301

39. Vallurupalli K, Atwell TD, Krambeck AE, Traynor KD, Broun D, Leroy AJ (2013) Pearls and pitfals in sonographic imaging of symptomatic urolithiasis in pregnancy. Ultrasound Q 29(1):51-59

40. Shokeir AA, Mahran MR, Abdulmaaboud M (2000) Renal colic in pregnant women: role of renal resistive index. Urology 55:344-347

41. Hertzberg BS, Carroll BA, Bowie JD, Paine SS, Kliewer MA, Paulson EK et al (1993) Doppler US assessment of maternal kidneys: analysis of intrarenal resistivity indexes in normal pregnancy and physiologic pelvicaliectasis. Radiology 186(3):689-692

42. Abramowicz JS, Kossoff G, Marsal K, Ter Haar G (2003) Safety statement, 2000 (reconfirmed 2003). International society of ultrasound in obstetrics and gynecology (ISUOG). Ultrasound Obstet Gynecol 2003(21):100 
43. Edwards MJ, Shiota K, Smith MS, Walsh DA (1995) Hyperthermia and birth defects. Reprod Toxicol 9:411-425

44. Salvesen KA (2002) EFSUMB: safety tutorial: epidemiology of diagnostic ultrasound exposure during pregnancy-European committee for medical ultrasound safety (ECMUS). Eur J Ultrasound 15:165-171

45. McClintic AM, King BH, Webb SJ, Mourad PD (2014) Mice exposed to diagnostic ultrasound in utero are less social and more active in social situations relative to controls. Autism Res 7:295-304

46. Barnett SB (1998) World federation for ultrasound in medicine and biology symposium on safety of ultrasound in medicine: recommendation on the safe use of ultrasound. Ultrasound Med Biol 24(suppl 1):1-55

47. Church CC, Miller MW (2007) Quantification of risk from fetal exposure to diagnostic ultrasound. Prog Biophys Mol Biol 93:331-353

48. European Committee for Medical Ultrasound Safety (ECMUS) (1999) Thermal teratology. Eur J Ultrasound 9:281-283

49. Bly S, Van den Hof MC, Diagnostic Imaging Committee SoO, Gynaecologists of C (2005) Obstetric ultrasound biological effects and safety. J Obstet Gynaecol Can 27:572-580

50. Pfaffenberger S, Vyskocil E, Kollmann C, Unger E, Kaun C et al (2013) Transtemporal ultrasound application potentially elevates brain temperature: results of an anthropomorphic skull model. Ultraschall Med 34:51-57

51. Horder MM, Barnett SB, Vella GJ, Edwards MJ, Wood AK (1998) In vivo heating of the guinea-pig fetal brain by pulsed ultrasound and estimates of thermal index. Ultrasound Med Biol 24:1467-1474

52. Jensh RP, Brent RL (1999) Intrauterine effects of ultrasound: animal studies. Teratology 59:240-251

53. Deyoe LA, Cronan JJ, Breslaw BH et al (1995) New techniques of ultrasound and color doppler in the prospective evaluation of acute renal obstruction: do they replace the intravenous urogram? Abdom Imaging 20:58-63

54. Wachsberg RH (1998) Unilateral absence of ureteral jets in the third trimester of pregnancy: pitfall in color Doppler US diagnosis of urinary obstruction. Radiology 209(1):279-281

55. Brent RL (1989) The effect of embryonic and foetal exposure to X-ray, microwaves, and ultrasound: counselling the pregnant and nonpregnant patient about these risks. Semin Oncol 16:347-368.

56. Swartz HM, Reichling BA (1978) Hazards of radiation exposure for pregnant women. JAMA 239:1907-1908

57. Harvey EB, Boice JD Jr, Honeyman M, Flannery JT (1985) Prenatal X-ray exposure and childhood cancer in twins. N Engl J Med 312:541-545

58. Brent RL, Mettler FA (2004) Pregnancy policy. Am J Roentgenol 182(3):819-822

59. American College of Obstetricians and Gynecologists Guidelines for diagnostic imaging during pregnancy and lactation. Committee Opinion No. 723 Obstet Gynecol, 130 (2017), pp e210-e216

60. White WM, Zite NB, Gash J, Waters WB, Thompson W, Klain FA (2007) Low-dose computed tomography for the evaluation of flank pain in the pregnant population. J Endourol 21(11):1255-1260

61. Travassos M, Amselem I, Filho NS, Miguel M, Sakai A, Consolmagno $\mathrm{H}$ et al (2009) Ureteroscopy in pregnant women for ureteral stone. J Endourol. 23(3):405-407

62. Masselli G, Derchi L, McHugo J, Rockall A, Vock P, Weston M et al (2013) Acute abdominal and pelvic pain in pregnancy: ESUR recommendations. ESUR Female Pelvic Imaging Subcommittee. Eur Radiol 23(12):3485-3500

63. McCollough CH, Schueler BA, Atwell TD et al (2007) Radiation exposure and pregnancy: when should we be concerned? Radiographics 27:909

64. Kulkarni NM, Uppot RN, Eisner BH, Sahani DV (2012) Radiation dose reduction at multidetector $C T$ with adaptive statistical iterative reconstruction for evaluation of urolithiasis: how low can we go? Radiology 265(1):158-166

65. White WM, Johnson EB, Zite NB, Beddies J, Krambeck AE, Hyams E et al (2013) Predictive value of current imaging modalities for the detection of urolithiasis during pregnancy: a multicenter, longitudinal study. J Urol 189:931-934

66. Fulgham PF, Assimos DG, Pearle MS (2013) Preminger Clinical effectiveness protocols for imaging in the management of ureteral calculous disease: AUA technology assessment. J Urol 189:1203-1213
67. Cobben LP, Groot I, Haans L, Blickman JG, Puylaert J (2004) MRI for clinically suspected appendicitis during pregnancy. AJR Am J Roentgenol 183(3):671-675

68. Masselli G, Derme M, Bernieri MG, Polettini E, Casciani E, Monti R et al (2014) Stone disease in pregnancy: imaging-guided therapy. Insights Imaging 5(6):691-696

69. Mullins JK, Semins MJ, Hyams ES et al (2012) Half fourier single shot turbo spin echo magnetic resonance urography for the evaluation of suspected renal colic in pregnancy. Urology 79(6):1252-1255

70. Regan F, Bohlman ME, Khazan R et al (1996) MR urography using HASTE imaging in the assessment of ureteric obstruction. AJR Am J Roentgenol 167:1115

71. Regan F, Kuszyk B, Bohlman ME et al (2005) Acute ureteric calculus obstruction: unenhanced spiral CT versus HASTE MR urography and abdominal radiograph. Br J Radiol 78:506

72. Spencer JA, Chahal R, Kelly A, Taylor K, Eardley I, Lloyd SN (2004) Evaluation of painful hydronephrosis in pregnancy: magnetic resonance urographic patterns in physiological dilatation versus calculous obstruction. J Urol 171(1):256-260

73. Semins JM, Matlaga BR (2013) Management of urolithiasis in pregnancy. Int J Womens Health 5:599-604

74. Cheek TG, Baird E (2009) Anesthesia for nonobstetric surgery: maternal and fetal considerations. Clin Obstet Gynecol 99:535-545

75. Burdan F, Starosławska E, Szumiło J (2012) Prenatal tolerability of acetaminophen and other over-the-counter non-selective 93 cyclooxygenase inhibitors. Pharmacol Rep 64:521-527

76. Broussard CS, Rasmussen SA, Reefhuis J, Friedman JM, Jann MW, RiehleColarusso T et al (2011) Maternal treatment with opioid analgesics and risk for birth defects. Am J Obst 204:e1-e11

77. Xue $P$, Tu C, Wang K, Wang $X$, Fang $Y$ (2013) Intracutaneous sterile water injection versus oral paracetamol for renal colic during pregnancy: a randomized controlled trial. Int Urol Nephrol 45(2):321-325

78. Razvi H, Bensalah K, Peyronnet B, Gross A, Krambeck A, Smith A et al (2014) Stones in special situations. In: Denstedt J, Rosette J (eds) Stone disease. Societe Internationale d'Urologie (SIU), Montreal, pp 409-501

79. Meria P, Hadjadj H, Jungers P, Members of the French Urological Association Urolithiasis Committee (2010) Stone formation and pregnancy: pathophysiological insights gained from morphoconstitutional stone analysis. J Urol 183(4):1412-1416

80. Semins MJ, Matlaga BR (2014) Kidney stones during pregnancy. Nat Rev Urol 11(3):163-168

81. Burgess KL, Gettman MT, Rangel LJ, Krambeck AE (2011) Diagnosis of urolithiasis and rate of spontaneous passage during pregnancy. J Urol 186:2280-2284

82. Preminger GM, Tiselius HG, Assimos DG et al (2007) Guideline for the management of ureteral calculi. Eur Urol 52:1610-1631

83. Assimos D, Krambeck A, Miller NL, Monga M, Murad MH, Nelson CP et al (2016) Surgical management of stones: american urological association/endourological society guideline. Part IIJ Urol 196:1161-1169

84. Dellabella M, Milanese G, Muzzonigro G (2005) Randomized trial of the efficacy of tamsulosin, nifedipine and phloroglucinol in medical expulsive therapy for distal ureteral calculi. J Urol 174:167

85. McClinton S, Starr K, Thomas R et al (2014) Use of drug therapy in the management of symptomatic ureteric stones in hospitalized adults (SUSPEND), a multicenter, placebo-controlled, randomized trial of a calcium-channel blocker (nifedipine) and an a-blocker (tamsulosin): study protocol for a randomized controlled trial. Trials 15:238

86. Weber-Schoendorfer C, Hannemann D, Meister R, Elefant E, CuppersMaarschalkerweerd B, Arnon J et al (2008) The safety of calcium channel blockers during pregnancy: a prospective, multicenter, observational study. Reprod Toxicol 26:24-30

87. Bailey G, Vaughan L, Rose C, Krambeck A (2016) Perinatal out- comes with tamsulosin therapy for symptomatic urolithiasis. J Urol 195:99

88. Lloyd GL, Lim A, Hamoui $\mathrm{N}$ et al (2016) The use of medical expulsive therapy during pregnancy: a worldwide perspective among experts. J Endourol 30:354-358

89. Bani Hani MN (2007) Laparoscopic surgery for symptomatic cholelithiasis during pregnancy. Surg Laparosc Endosc Percutan Tech 17(6):482-486 
90. Corneille MG, Gallup TM, Bening T et al (2010) The use of laparoscopic surgery in pregnancy: evaluation of safety and efficacy. Am J Surg 200(3):363-367

91. Erekson EA, Brousseau EC, Dick-Biascoechea MA, Ciarleglio MM, Lockwood CJ, Pettker CM (2012) Maternal postoperative complications after nonobstetric antenatal surgery. J Matern Fetal Neonatal Med 25(12):2639-2644

92. Assimos D, Krambeck A, Miller NL et al (2016) Surgical management of stones: American Urological Association/Endourological Society guideline. Part I. J Urol 196:1153-1160

93. Rana AM, Aquil S, Khawaja AM (2009) Semirigid ureteroscopy andpneumatic lithotripsy as definitive management of obstructive ureteralcalculi during pregnancy. Urology 73:964-967

94. Khoo L, Anson K, Patel U (2004) Success and short-term complication rates of percutaneous nephrostomy during pregnancy. J Vasc Interv Radiol 15(12):1469-1473

95. Jarrard DJ, Gerber GS, Lyon ES (1993) Management of acute ureteral obstruction in pregnancy utilizing ultrasoundguided placement of ureteral stents. Urology 42(3):263-268

96. Isen K, Hatipoglu NK, Dedeoglu S, Atilgan I, Caça FN, Hatipoglu N (2012) Experience with the diagnosis and management of symptomatic ureteric stones during pregnancy. Urology 79(3):508-512

97. Song Y, Xiang F, Yongsheng $S$ (2013) Diagnosis and operative intervention for problematic ureteral calculi during pregnancy. Int J Gynaecol Obstet 121:115-118

98. Rivera ME, McAlvany KL, Brinton TS et al (2014) Anesthetic exposure in the treatment of symptomatic urinary calculi in pregnant women. Urology 84:1275-1278

99. Zhou L, Cai X, Li H et al (2015) Effects of a-blockers, antimuscarinics, or combination therapy in relieving ureteral stent-related symptoms: a meta-analysis. J Endourol 29:650-656

100. Pearle MS, Pierce HL, Miller GL, Summa JA, Mutz JM, Petty BA et al (1998) Optimal method of urgent decompression of the collecting system for obstruction and infection due to ureteral calculi. J Urol 160:1260-1264

101. Dion M, Violette P, Razvi H (2014) Managing stones in pregnancy: an update. Clin Pract 11:699-710

102. Johnson EB, Krambeck AE, White WM et al (2012) Obstetric complications of ureteroscopy during pregnancy. J Urol 188:151-154

103. Scarpa RM, De Lisa A, Usai E (1996) Diagnosis and treatment of ureteral calculi during pregnancy with rigid ureteroscopes. J Urol 155:875-877

104. Deters LA, Belanger $G$, Shah $O$ et al (2013) Ultrasound guided ureteroscopy in pregnancy. Clin Nephrol 79:118-123

105. Committee on Obstetric Practice and the American Society of Anesthesiologists. Committee Opinion No. 696: nonobstetric surgery during pregnancy. Obstet Gynecol 2017; 129: 777-778

106. Wymer K, Plunkett BA, Park S (2015) Urolithiasis in pregnancy: a costeffectiveness analysis of ureteroscopic management vs ureteral stenting. Am J Obstet Gynecol 213:691e1-691e8

107. Watterson JD, Girvan AR, Beiko DT et al (2002) Ureteroscopy and holmium: yag laser lithotripsy: an emerging definitive management strategy for symptomatic ureteral calculi in pregnancy. Urology 60(3):383-387
108. Ulvik NM, Bakke A, Hoisaeter PA (1995) Ureterscopy in pregnancy. J Urol 154(5):1660-1663

109. Bozkurt Y, Soylemez H, Atar M et al (2013) Effectiveness and safety of ureteroscopy in pregnant women: a comparative study. Urolithiasis 41(1):37-42

110. Smith D, Graham J, Prystowsky JB, Dalkin BL, Nemcek AA Jr (1992) The effects of ultrasound guided shock waves early in pregnancy in Sprague-Dawley rats. J Urol 147:1197-1207

111. Wang Z, Le X, Su Z, Yao C, Chen Z (2014) Invasive management of proximal ureteral calculi during pregnancy. Urology 83(4):745-749

112. Atar M, Bozkurt Y, Soylemez $\mathrm{H}$ et al (2012) Use of renal resistive index and semi-rigid ureterscopy for managing symptomatic persistent hydronephrosis during pregnancy. Int J Surg 10(10):629-633

113. Smith CL, Kristensen C, Davis M et al (2001) An evaluation of the physicochemical risk for renal stone disease in pregnancy. Clin Nephrol 55:205-211

114. Zhang Shilin, Liu Guoqing, Duo Yongfu, Wang Jianfeng, Li Jierong, Li Chunjing (2016) Application of ureteroscope in emergency treatment with persistent renal colic patients during pregnancy. PLOS ONE 11(1):e0146597

115. Fregonesi A, Dias FG, Saade RD et al (2013) Challenges on percutaneous nephrolithotomy in pregnancy: supine position approach through ultrasound guidance. Urol Ann 5:197-199

116. Toth C, Toth G, Varga A et al (2005) Percutaneous nephrolithotomy in early pregnancy. Int Urol Nephrol 37:1-3

117. Yalcin O, Tahmaz L, Yumbul Z et al (1998) Effects of shock waves on a rat foetus. Scand J Urol Nephrol 32:167-170

118. Ohmori K, Matsuda T, Horii Y et al (1994) Effects of shock waves on the mouse fetus. J Urol 151:255-258

119. Gumus B, Lekili M, Kandiloglu AR et al (1997) Effects of extracorporeal shockwave lithotripsy at different stages of pregnancy in the rabbit. J Endourol 11(5):323-326

120. Chaussy CG, Fuchs GJ (1989) Current state and future developments of noninvasive treatment of human urinary stones with extracorporeal shock wave lithotripsy. J Urol 141:782-789

121. Asgari MA, Safarinejad MR, Hosseini SY, Dadkhah F (1999) Extracorporeal shock wave lithotripsy of renal calculi during early pregnancy. BJU Int 84:615-617

122. Paterson R, Fernandez A, Razvi H, Sutton R (2010) Evaluation and medical management of the kidney stone patient. Can Urol Assoc Guidel CUAJ 4(6):375-379

123. Banhidy F, Acs N, Puho E, Czeizel AE (2007) Maternal kidney stones during pregnancy and adverse birth outcomes, particularly congenital abnormalities in the offspring. Arch Gynecol Obstet 275(6):481-487

124. Chung SD, Chen YH, Keller JJ, Lin CC, Lin HC (2012) Urinary calculi increase the risk for adverse pregnancy outcomes: a nationwide study. Acta Obstet Gyenecol 92(1):69-74

\section{Publisher's Note}

Springer Nature remains neutral with regard to jurisdictional claims in published maps and institutional affiliations. 